\title{
Preventive health service coverage among infants and children at six maternal-child health clinics in western Kenya: A cross-sectional assessment
}

Andrew Deathe ( $\square$ ardeathe@gmail.com )

Centers for Disease Control and Prevention https://orcid.org/0000-0002-1975-7519

\section{Eren Oyungu}

Moi University

Samuel 0. Ayaya

Moi University

Ananda R. Ombitsa

Moi University

Carole I. McAteer

Indiana University Department of Pediatrics

Rachel C. Vreeman

AMPATH Kenya

Megan S. McHenry

Indiana University Department of Pediatrics

\section{Research article}

Keywords: child health, health service coverage, Kenya, sub-Saharan Africa, immunizations, maternal and child health

Posted Date: January 15th, 2020

DOI: https://doi.org/10.21203/rs.2.20918/v1

License: (a) (i) This work is licensed under a Creative Commons Attribution 4.0 International License. Read Full License

Version of Record: A version of this preprint was published at Maternal and Child Health Journal on October 29th, 2021. See the published version at https://doi.org/10.1007/s10995-021-03271-8. 


\section{Abstract}

\section{Background}

Despite the substantial reduction of child mortality in recent decades, Kenya still strives to provide universal healthcare access and to meet other international benchmarks for child health. This study aimed to describe child health service coverage among children visiting six Maternal and Child Health $(\mathrm{MCH})$ clinics in western Kenya.

\section{Methods}

In a cross-sectional study of Kenyan young children ( $\leq 5$ years) presenting to $\mathrm{MCH}$ clinics, child health records were reviewed to determine coverage of immunizations, growth monitoring, vitamin A supplementation, and deworming. Among 78 children and their caregivers, nearly $70 \%$ of children were fully vaccinated for their age.

\section{Results}

We found a significant disparity in full vaccination coverage by gender $(p=.017)$, as males had $3.5 x$ higher odds of being fully vaccinated compared to females. Further, full vaccination coverage also varied across $\mathrm{MCH}$ clinic sites ranging from $43.8 \%$ to $92.9 \%$.

\section{Conclusions}

Health service coverage for Kenyan children in this study is consistent with national and sub-national findings; however, our study found a significant gender equity gap in coverage at these six clinics that warrants further investigation to ensure that all children receive critical preventative services.

\section{Background}

In 2016, nearly six million children under five years of age globally died (1). Despite being home to nearly $14 \%$ of the world's population, sub-Saharan Africa (SSA) accounts for nearly 3.2 million of these deaths (1). Further, the under-five mortality rate in Kenya is 49 deaths per 1,000 live births (1). The most significant causes of mortality in children under five years of age in Kenya are preventable or treatable conditions (2). In Kenya, Maternal-Child Health (MCH) clinics are the primary source of healthcare for infants. $\mathrm{MCH}$ clinics provide services to prevent and treat diseases, including immunizations, vitamin $\mathrm{A}$ supplementation, deworming, and growth monitoring, as well as serve as a source of educational knowledge about health-related topics. Inadequate provision of or access to these services during the prenatal, perinatal, and early childhood periods contributes to unnecessary infant and child deaths (3). A previous study found that increasing interventions and services within the maternal and child health care continuum are largely responsible for the decline in childhood mortality. Therefore, monitoring coverage of these interventions and services is critical to determine gaps and barriers affecting service provision (4). 
In Kenya, preventative services, such as immunizations, vitamin A, and deworming, are reported on national and regional levels within the Kenya Demographic and Health Survey (KDHS), most recently published in 2015 (5). However, national coverage estimates may not accurately depict situations at the local levels, due to population-based sampling. To achieve the ambitious targets of the Sustainable Development Goals, high quality preventive healthcare services must be accessible for all children. Therefore, it is necessary to address inequalities and disparities affecting the access, utilization, delivery, and subsequent coverage of services provided to children. Identifying the services that are provided at these $\mathrm{MCH}$ clinics, the coverage of services, and any gaps that may prevent children from receiving the critically important care is a crucial first step in moving Kenya forward in the new Sustainable Development Goals era.

Within the health records, Kenya's Ministry of Health prioritizes weight and height measurements, immunizations, deworming, and vitamin A supplementation as key areas for preventative healthcare for children under the age of five years. Therefore, we assessed these key areas in this study (6). The objective of the study was to determine the coverage of services and interventions provided to infants and children at six maternal and child health clinics in western Kenya in order to identify gaps in the services with the ultimate goal of identifying factors that may be associated with lower coverage.

\section{Methods}

This cross-sectional descriptive study was performed at six MCH clinics located within Bungoma, Nandi, Trans Nzoia, and Uasin Gishu counties located in western Kenya. The clinics are located in the towns of Eldoret, Turbo, Webuye, Mosoriot, Burnt Forest, and Kitale. These Ministry of Health clinics work in close collaboration with an institutional partnership: Academic Model Providing Access to Healthcare (AMPATH). This institutional partnership isled by Moi University School of Medicine and Indiana University and aims to improve delivery of healthcare services in western Kenya (7). This existing partnership and their close collaboration with the local $\mathrm{MCH}$ clinics throughout the region provided the rationale for the selection of the study setting. This study was approved by the ethical committees of both Indiana University and Moi University. Moi University's Institutional Research and Ethics Committee is registered with the U.S. Office of Human Research Protections with its own Federalwide Assurances.

From 11/7/2016 - 12/7/2016, caregivers were recruited for participation at six MCH clinic locations using convenience sampling. A research assistant attended a full pediatric clinic day and approached all caregivers meeting the following inclusion criteria: bringing a child under the age of five years to be seen and identifying their current location as their primary $\mathrm{MCH}$ clinic. Every present caregiver who met inclusion criteria was recruited. A total of 78 caregivers consented and agreed to participate in the study. Only one recruited caregiver declined participation. For each caregiver, the child brought to clinic was also included in the study. Only retrospective data were collected from the children's medical record.

The Mother and Child Health Booklet was the primary data source for this study. This booklet contains the services and interventions received by the child at the $\mathrm{MCH}$ clinic. Kenya began using The Mother and 
Child Health Booklet in 2008 to link maternal and child healthcare and have one comprehensive medical record (6). The Mother and Child Health Booklet provides education on strategies to improve her and her child's health. The book, which is the primary health record for the mother and her child, is brought to every visit with a healthcare provider. Healthcare providers record services and interventions provided at each visit in the booklet.

In Kenya, children are immunized against tuberculosis, diphtheria, whooping cough (pertussis), tetanus, polio, measles, hepatitis B, Haemophilus influenza type b (Hib), Streptococcus pneumonia, and rotavirus (5). Bacillus Calmette-Guerin (BCG) is used for immunization again tuberculosis. The pentavalent vaccine provides protection against diphtheria, pertussis, tetanus, hepatitis $\mathrm{B}$, and Hib. The administration of the oral polio vaccine (OPV) immunizes again poliovirus, and measles and rotavirus each have their own vaccine. Lastly, children are vaccinated against Streptococcus pneumoniae via administration of the pneumococcal conjugate vaccine (PCV) (5). Among the six vaccines included in the routine immunization schedule in Kenya, all but one, BCG, is given in a series of multiple doses.

To prevent soil-transmitted helminth infections, which are associated with malnutrition, poor physical growth, and cognitive impairment $(8,9)$, the World Health Organization and Kenya's Ministry of Health recommends children ages 12-59 months receive one dose of either albendazole or mebendazole every 6 months. Additionally, vitamin A deficiency affects nearly $30 \%$ of children in low- and middle-income countries and is linked to child mortality (10). To prevent vitamin A deficiency, high-dose vitamin A is given once every 6 months as a supplement, beginning at 6 months of age and ending at 59 months of age (5).

For data collection, brief oral interviews with caregivers and review of the Mother and Child Health Booklet were utilized. Structured oral interviews captured demographic data, such as their relationship with the child, age, and whether or not other children lived in the household. Interviews were conducted in either English or Kiswahili, whichever the participant felt most comfortable speaking. A research assistant was trained to ask questions and to categorize the responses into the pre-assigned answer choices. A free text option was available if the study team member found that available categories were not appropriate. Retrospective data collection was performed to ascertain health services related data for each child. These data were directly collected from the child's Mother and Child Health Booklet. A research assistant reviewed the Mother and Child Health Booklets for immunizations, vitamin A supplementation, deworming, and growth monitoring. For immunizations, a research assistant also recorded the child received each dose in each vaccine series and time point or visit for vitamin A supplementation, deworming, and growth monitoring. For all health services data, eligibility for health services was verified by referencing the age of the child, presence at $\mathrm{MCH}$ clinic, and timing of service delivery.

Following the conclusion of data collection, health services records extracted from the Mother and Child Health Booklets and responses from the caregiver questionnaires were entered into a Microsoft Excel file. For immunizations, variables were created for each vaccine series to determine whether each child was 
up-to-date for each vaccine, as defined for each vaccine as the eligibility of child receiving every dose in the series based on age. For example, if a child was 12-weeks old and she received the first three doses of OPV (at birth, 6 weeks, and 10 weeks), she was determined to be up-to-date on OPV despite not receiving the last dose (given at 14-weeks). An additional variable was created to account for every vaccine and series in the immunization schedule. If a child received all vaccines and was up-to-date on all series in the immunization schedule, she was considered up-to-date on all vaccines and fully vaccinated for her age. Similar variables were created for vitamin A supplementation, deworming, and growth monitoring of weight. Height was not accounted for in the growth monitoring variable because only $30 \%$ of children had any height measurements recorded.

Statistical Analysis

Descriptive statistics were used to analyse the responses from the caregiver questionnaire and the proportion of children who received health services and those up-to-date (having received all services they were eligible for). These health services included immunizations, vitamin A supplementation, deworming, and growth monitoring. Additionally, a drop-out rate was calculated for the pentavalent vaccine, which is the proportion of children receiving the first dose in the series but not the third if eligible. Pentavalent drop-out rates are a common way to measure access to services and the capacity of health systems (i.e. $\mathrm{MCH}$ clinics) to provide services that require multiple visits (11). Pearson's chi-square test was applied to determine significant differences in the proportion of males and females up-to-date on all vaccines, vitamin A supplementation, deworming, and weight measurement. Similarly, chi-square was also performed to determine differences in proportion of children fully immunized for age between households with or without other children at home, those who travelled more than 30 minutes to clinic and those who travelled less, different methods of transport, and those who reported barriers in accessing services at the clinic. All analyses were conducted using SPSS (version 24) (12).

\section{Results}

The background characteristics for both the caregivers and children are presented in Table 1. The majority of caregivers were mothers of the children brought to clinic (98.7\%), while one caregiver identified as household help. Nearly half of all caregivers (46.2\%) were between the ages of $25-29$ years, and $61.5 \%$ had more than one child. Among the children included in the study, gender was evenly distributed $(50 \%)$ and the mean age was 22.0 weeks (range $=1-104)$. Only four children were over the age of 12 months. $\mathrm{MCH}$ clinics in Turbo and Mosoriot had the most caregivers $(n=17$ and $n=16$, respectively) followed by Kitale $(n=14)$, Burnt Forest $(n=11)$, Eldoret $(n=10)$, and Webuye $(n=10)$.

\section{Table 1. Participant Characteristics}




\begin{tabular}{|c|c|}
\hline Variable & $\mathrm{n}(\%)$ \\
\hline \multicolumn{2}{|c|}{ Caregiver's Relationship to Child } \\
\hline Mother & $77(98.7)$ \\
\hline Household Help & $1(1.3)$ \\
\hline \multicolumn{2}{|c|}{ Caregiver's Age (in years) } \\
\hline$<20$ & $1(1.3)$ \\
\hline $20-24$ & $16(20.5)$ \\
\hline $25-29$ & $36(46.2)$ \\
\hline $30-34$ & $17(21.8)$ \\
\hline $35-39$ & $6(7.7)$ \\
\hline Over 40 & $2(2.6)$ \\
\hline \multicolumn{2}{|c|}{ Other Children in the Home } \\
\hline Yes & $48(61.5)$ \\
\hline No & $30(38.5)$ \\
\hline \multicolumn{2}{|c|}{ Gender of Child } \\
\hline Male & $39(50.0)$ \\
\hline Female & $39(50.0)$ \\
\hline \multicolumn{2}{|c|}{ Age of Child (in months) } \\
\hline$<1$ & $13(16.7)$ \\
\hline $1-3$ & $29(37.2)$ \\
\hline $4-6$ & $14(17.9)$ \\
\hline $7-9$ & $8(10.3)$ \\
\hline $10-12$ & $10(12.8)$ \\
\hline$>12$ & $4(5.1)$ \\
\hline \multicolumn{2}{|c|}{ Age of Child (in weeks) } \\
\hline & an: 22.0 \\
\hline \multicolumn{2}{|c|}{ MCH Site Recruitment } \\
\hline Eldoret & 10 \\
\hline Turbo & 17 \\
\hline Webuye & 10 \\
\hline Mosoriot & 16 \\
\hline Burnt Forest & 11 \\
\hline \multicolumn{2}{|l|}{ Kitale } \\
\hline & 14 \\
\hline \multicolumn{2}{|c|}{ Travel Time to MCH Clinic } \\
\hline$<30$ minutes & $27(34.6)$ \\
\hline 30 - 59 minutes & $28(35.9)$ \\
\hline
\end{tabular}


Over $80 \%(n=64)$ of children were first brought to clinic within the first 28 days of life. The most common forms of transportation used to reach clinic were motorbike (38.5\%) and walking (37.2\%), while the remaining $24.4 \%$ of caregivers used matatus, which are privately owned share taxis. The most common reasons for bringing their child to clinic were weight checks (62.8\%), immunizations (53.8\%), and routine health monitoring (39.7\%). Only $20.5 \%$ indicated vitamin A supplementation as a reason and $10.3 \%$, listed seeking treatment for illness. When asked what types of services their $\mathrm{MCH}$ clinic offered, most caregivers (98.7\%) listed growth monitoring, while $48.7 \%$ and $37.2 \%$ listed immunizations and nutrition, respectively. Only $7.7 \%$ listed vitamin A supplementation, and two caregivers $(2.3 \%)$ said their $\mathrm{MCH}$ clinic offered educational health talks and teaching for mothers.

\section{Immunizations}

Individual dose coverage for all vaccines ranged from $84.4 \%$ to $100 \%$. The third dose of OPV and second dose of measles vaccines had the highest coverage at $100 \%$, while the first dose of rotavirus vaccine had the lowest (84.4\%). Out of fifteen total doses of vaccine given, only four doses had coverage below $90 \%$ (Fig 1). The drop-out rate for the pentavalent vaccine was $6.7 \%$. Among all vaccines incorporating a 10week dose in their series (OPV, pentavalent, PCV, and rotavirus), the dose with the highest coverage was the 10-week for all vaccines, regardless of whether it was the second (pentavalent, PCV, rotavirus) or third (OPV) dose in the series.

After accounting for varying child age and eligibility for vaccines, the proportion of children up-to-date on each vaccine was calculated (Table 2). BCG vaccine given at birth had the highest coverage of all vaccines (94.9\%), while PCV and rotavirus had the lowest coverage (each $82.8 \%$ ). The proportions of children up-to-date on pentavalent, OPV, and measles were $92.2 \%, 85.9 \%$, and $88.9 \%$, respectively. A lesser proportion of females were up-to-date on all vaccines, with the exception of BCG and measles, which had the same coverage as males. Across all $\mathrm{MCH}$ sites, Mosoriot was the only site where coverage fell below $80 \%$ for any single vaccine. At this site, less than $80 \%$ of children were up-to-date on OPV (68.8\%), PCV (66.7\%), and rotavirus (66.7\%).

\section{Table 2. Number and Percent of Children Up-to-Date on Vaccines by Gender and MCH Site}




\begin{tabular}{|c|c|c|c|c|c|c|c|}
\hline & $\begin{array}{c}\text { BCG } \\
n \\
(\%) \\
\end{array}$ & $\begin{array}{c}\text { OPV } \\
\text { n } \\
(\%) \\
\end{array}$ & $\begin{array}{c}\text { Pentavalent } \\
\mathrm{n} \\
(\%) \\
\end{array}$ & $\begin{array}{c}\text { PCV } \\
\text { n } \\
(\%)\end{array}$ & $\begin{array}{c}\text { Measles } \\
\mathrm{n} \\
(\%) \\
\end{array}$ & $\begin{array}{c}\text { Rotavirus } \\
\qquad \mathrm{n} \\
(\%) \\
\end{array}$ & $\begin{array}{c}\text { Fully Vaccinated } \\
\qquad \mathrm{n} \\
(\%) \\
\end{array}$ \\
\hline Sex & & & & & & & \\
\hline Male & $\begin{array}{l}37 / 39 \\
(94.9)\end{array}$ & $\begin{array}{l}36 / 39 \\
(92.3)\end{array}$ & $\begin{array}{l}33 / 33 \\
(100)\end{array}$ & $\begin{array}{l}31 / 33 \\
(93.9)\end{array}$ & $\begin{array}{c}8 / 9 \\
(88.9)\end{array}$ & $\begin{array}{l}28 / 33 \\
(84.8)\end{array}$ & $\begin{array}{l}32 / 39 \\
(82.1)\end{array}$ \\
\hline Female & $\begin{array}{r}37 / 39 \\
(94.9)\end{array}$ & $\begin{array}{l}31 / 39 \\
(79.5)\end{array}$ & $\begin{array}{r}26 / 31 \\
(83.9) \\
\end{array}$ & $\begin{array}{c}22 / 31 \\
(71) \\
\end{array}$ & $\begin{array}{r}8 / 9 \\
(88.9) \\
\end{array}$ & $\begin{array}{l}25 / 31 \\
(80.6) \\
\end{array}$ & $\begin{array}{l}22 / 39 \\
(56.4)\end{array}$ \\
\hline $\begin{array}{c}\text { MCH Site } \\
\text { Eldoret }\end{array}$ & $\begin{array}{l}10 / 10 \\
(100)\end{array}$ & $\begin{array}{l}9 / 10 \\
(90)\end{array}$ & $\begin{array}{l}10 / 10 \\
(100)\end{array}$ & $\begin{array}{l}9 / 10 \\
(90)\end{array}$ & $\begin{array}{c}1 / 1 \\
(100)\end{array}$ & $\begin{array}{l}9 / 10 \\
(90)\end{array}$ & $\begin{array}{l}8 / 10 \\
(80)\end{array}$ \\
\hline Turbo & $\begin{array}{l}14 / 17 \\
(82.4)\end{array}$ & $\begin{array}{l}15 / 17 \\
(88.2)\end{array}$ & $\begin{array}{l}12 / 13 \\
(92.3)\end{array}$ & $\begin{array}{l}11 / 13 \\
(84.6)\end{array}$ & $\begin{array}{c}8 / 8 \\
(100)\end{array}$ & $\begin{array}{l}11 / 13 \\
(84.6)\end{array}$ & $\begin{array}{l}11 / 17 \\
(64.7)\end{array}$ \\
\hline Webuye & $\begin{array}{l}10 / 10 \\
(100)\end{array}$ & $\begin{array}{l}10 / 10 \\
(100)\end{array}$ & $\begin{array}{r}5 / 5 \\
(100)\end{array}$ & $\begin{array}{r}5 / 5 \\
(100)\end{array}$ & $\begin{array}{l}0 / 0 \\
(0)\end{array}$ & $\begin{array}{c}5 / 5 \\
(100)\end{array}$ & $\begin{array}{l}8 / 10 \\
(80)\end{array}$ \\
\hline Mosoriot & $\begin{array}{l}15 / 16 \\
(93.8)\end{array}$ & $\begin{array}{l}11 / 16 \\
(68.8)\end{array}$ & $\begin{array}{l}14 / 15 \\
(93.3)\end{array}$ & $\begin{array}{l}10 / 15 \\
(66.7)\end{array}$ & $\begin{array}{c}2 / 2 \\
(100)\end{array}$ & $\begin{array}{l}10 / 15 \\
(66.7)\end{array}$ & $\begin{array}{r}7 / 16 \\
(43.8)\end{array}$ \\
\hline Burnt Forest & $\begin{array}{l}11 / 11 \\
(100)\end{array}$ & $\begin{array}{l}9 / 11 \\
(81.8)\end{array}$ & $\begin{array}{l}9 / 11 \\
(81.8)\end{array}$ & $\begin{array}{l}9 / 11 \\
(81.8)\end{array}$ & $\begin{array}{r}5 / 5 \\
(100)\end{array}$ & $\begin{array}{l}10 / 11 \\
(90.9)\end{array}$ & $\begin{array}{r}7 / 11 \\
(63.6)\end{array}$ \\
\hline Kitale & $\begin{array}{l}14 / 14 \\
(100)\end{array}$ & $\begin{array}{l}13 / 14 \\
(92.9)\end{array}$ & $\begin{array}{l}9 / 10 \\
(90)\end{array}$ & $\begin{array}{l}9 / 10 \\
(90)\end{array}$ & $\begin{array}{l}0 / 0 \\
(0)\end{array}$ & $\begin{array}{l}8 / 10 \\
(80)\end{array}$ & $\begin{array}{l}13 / 14 \\
(92.9)\end{array}$ \\
\hline Total & $\begin{array}{r}74 / 78 \\
(94.9)\end{array}$ & $\begin{array}{l}67 / 78 \\
(85.9)\end{array}$ & $\begin{array}{l}59 / 64 \\
(92.2)\end{array}$ & $\begin{array}{l}53 / 64 \\
(82.8)\end{array}$ & $\begin{array}{l}16 / 18 \\
(88.9)\end{array}$ & $\begin{array}{l}53 / 64 \\
(82.8)\end{array}$ & $\begin{array}{l}54 / 78 \\
(69.2)\end{array}$ \\
\hline
\end{tabular}


Slightly less than seventy percent (69.2\%) of children were up-to-date on all vaccines and fully vaccinated for their age. The only demographic factor found to be significantly associated with up-to-date vaccination status was gender, as males showed 3.5 times higher odds of being up-to-date for all vaccines compared to females [95\% $\mathrm{Cl} 1.256,9.936]$. More than 8 out of every 10 males (82.1\%) were upto-date on all vaccines compared to just $56.4 \%$ of females. Differences in the proportion of children up-todate on all vaccines were also found between $\mathrm{MCH}$ sites (Table 2). Among all $\mathrm{MCH}$ sites, Kitale had the highest proportion of children up-to-date on all vaccines and fully vaccinated for their age (92.9\%). In Eldoret and Webuye, $80 \%$ of children were up-to-date on all vaccines, while less than two-thirds were in Turbo (64.7\%) and Burnt Forest (63.6\%). Mosoriot had the lowest proportion (43.8\%).

\section{Vitamin A and Deworming}

Only $35.9 \%$ ( $n=28$ ) of children were eligible for vitamin A supplementation (VAS). Of these, over $75 \%$ ( $n=$ 21) received VAS at 6 months of age, while $50 \%$ received it at 12 months of age. All children received VAS at 18 and 24 months of age $(n=3, n=1$, respectively). Twenty-two $(78.6 \%)$ of children received every dose of VAS for which they were eligible. VAS coverage was similar between males (80\%) and females (77\%). Turbo and Burnt Forest were the only $\mathrm{MCH}$ sites where a child did not receive VAS. Only $3 / 7$ of children received VAS in Turbo, compared to $3 / 5$ in Burnt Forest. Of the six children eligible to receive deworming medicine at 12 months of age, one two (33.3\%) received this medicine. At 12 months, none of the four females eligible received deworming, while both males received this treatment. At 18 months of age, none of the three children eligible received deworming. One child was eligible for deworming at 24 months, and she received the medicine.

\section{Growth Monitoring}

Only one-third ( $\mathrm{n}=26)$ of children had a birthweight recorded, while $83.1 \%$ of children had a weight measurement recorded at six weeks of age. The majority (61.5\%) of children had a weight measurement recorded at all $\mathrm{MCH}$ visits. Two-thirds of males (66.7\%) had a weight recorded at every visit compared to $56.3 \%$ of females. Across $\mathrm{MCH}$ sites, Eldoret and Kitale had the highest proportions of weight recording, $100 \%$ and $90 \%$, respectively, while Burnt Forest $(22.2 \%$ ) and Turbo (30.8\%) had the lowest. Only $30.8 \%$ (n $=24$ ) of children had a height measurement recorded at one or more $\mathrm{MCH}$ clinic visits. None had a height measurement recorded at every $\mathrm{MCH}$ visit.

\section{Discussion}

This study aimed to assess the coverage of health services and interventions provided to infants and young children at six $\mathrm{MCH}$ clinics located in western Kenya. In this small cross-sectional study, we found that immunization coverage rates were consistent with regional data in Kenya's national surveys. However, these rates are still below the necessary coverage rates for adequate herd immunity. In addition, we found a gender gap and an inequitable distribution of vaccine coverage across $\mathrm{MCH}$ clinics in that males had higher coverage for immunizations and nearly all other services included in the study compared to females. 
Nearly $70 \%$ of children were up-to-date on all vaccines, which is comparable to national estimates in Kenya reported by the most recent KDHS (5). The KDHS reports $74.9 \%$ of Kenyan children are fully vaccinated. Individual vaccine coverage found in our study is also comparable to national estimates as the difference in coverage does not exceed $5 \%$ for any single vaccination (5). Subnational vaccine coverage estimates are also consistent with the findings of this study. in In the Rift Valley region of Kenya, the proportion of fully vaccinated children $(68.7 \%)$ is nearly identical to the findings of the present study (69.2\%) (5). In addition, individual vaccine coverage observed in this study more closely resembles the Rift Valley regions than national estimates. Measles coverage at the national (87.1\%) and subnational (Rift Valley) (83.1\%) levels, as well as in this study (88.9\%), are all well below the $95 \%$ threshold for achieving herd immunity (13).

The drop-out between the first and third pentavalent vaccine coverage for all $\mathrm{MCH}$ clinics was only $6.7 \%$. This drop-out rate is consistent with other studies in Kenya (14), and suggests that the six MCH clinics studied deliver effective immunization services as a whole. However, national and subnational data sources typically use population-based sampling rather than clinic-based, which was used in this study. Recruiting caregivers and their children from the clinic, a population already accessing services, could explain the higher vaccination coverage found in this study. The vaccination coverage rates for the six $\mathrm{MCH}$ clinics combined distort the poor coverage in individual clinics, as vaccination coverage varied significantly from site to site. In Mosoriot, less than half of children were considered fully vaccinated for their age. Further investigation is needed to determine factors related to poor vaccination coverage in certain $\mathrm{MCH}$ clinics.

Other studies in similar settings found that wealth (15-17), caregiver knowledge of immunization services (16), fewer children in the household $(18)$, skilled birth attendance $(17,19)$, high health worker performance (16), literacy (16), and parental education (18) was associated with higher vaccination coverage. In this study, factors such as a child's gender, age of caregiver, number of siblings, type and duration of transportation, and clinic site were assessed; however, only gender was found to be associated with vaccination rates. The small sample size and low power may have influenced the identification of associations within this study.

The finding that males in our study were more likely to be fully vaccinated than females is not consistent with recent KDHS reports and some studies, which showed no difference in coverage rates between males and females $(5,15,20)$. These studies were conducted at the national level $(5)$, in an urban setting (20), and in rural western Kenya (15). In our study, we found that males showed over 3.5 times the odds of being fully vaccinated for their age compared to females. A recent study conducted in Nairobi, Kenya also supported the presence of an immunization gender gap, finding that only $65.2 \%$ of females were fully vaccinated compared to $73.2 \%$ of their male counterparts (21). Similar to the gender disparity found in vaccination coverage, a lesser proportion of females received vitamin A supplementation and growth monitoring. While these differences were not as stark as the gender gap in vaccination coverage, they still raise concern and could indicate that female children do not have the same access to preventive health services as male children. Additional research is needed to ascertain whether caregivers are seeking the 
same care regardless of their child's gender in order to develop strategies to improve vaccination coverage in this region of Kenya that target female children to achieve equitable coverage. In future studies, the high coverage rate for vaccines and growth monitoring at 10-weeks of age will be considered as a highly compliant visit in $\mathrm{MCH}$ clinics. The completion rate of the 10-week dose was the highest among all vaccines in the series. In addition, the largest proportion of children receiving growth monitoring was at 10-weeks of age as well.

Vitamin A supplementation coverage among the children in the study was higher than findings from the most recent KDHS (5). According to this KDHS, $67.9 \%$ of children ages $6-8$ months received vitamin $A$ supplementation compared to $78.6 \%$ of children receiving vitamin A supplementation within this study at their 6-month visit. Coverage was similar among males and females within the KDHS as well (5).

Deworming coverage was lower in the sample than national estimates. Only one-third of children in the present study received deworming medicines in the last twelve months compared to $51 \%$ estimated in the most recent KDHS (5). Due to the youth of this study's sample, it was difficult to accurately measure and compare vitamin $A$ and especially deworming coverage rates to the national levels. The mean age of this sample was just over 5 months and children are not eligible to receive vitamin A supplementation and deworming medicines until 6 and 12 months of age, respectively. Additional data from an older sample of children are needed to provide an estimation of service vitamin A supplementation and deworming coverage.

A limitation of this study is that it was subject to sampling bias as participants were recruited at the $\mathrm{MCH}$ clinic. Only caregivers and children who were already present in the $\mathrm{MCH}$ clinic were eligible for inclusion in the study. Recruiting participants at the clinic excludes caregivers and children who do not have access to services, encounter barriers in accessing preventive health services, or are disengaged from care for other reasons. This sampling could potentially lead to an overestimation of service coverage because we were unable to account for the children not receiving any services. Additionally, recruiting at each $\mathrm{MCH}$ clinic site for just one day could potentially lead to a non-representative sample.

Another limitation was that the sampling strategy might be potential source of overestimating service coverage. For instance, it was difficult to determine whether the caregiver was just arriving or just leaving the clinic at the time of recruitment. Further, when reviewing the Mother and Child Health Booklet, it was assumed that all services were provided on the visit. Therefore, systematic bias was possible within the data source.

Other limitations that could lead to inaccurate coverage estimates include the age of the children in the sample and the sampling strategy. Due to the majority of the children in the sample being under one year of age, it was not possible to determine vaccination coverage in terms of the number of children receiving all required doses. Few children were old enough to have even been eligible to receive all vaccines, so coverage was defined by receipt of eligible vaccines. This could overestimate vaccine coverage because we were unable to account for potential future missed doses. Finally, the small sample size used in this study restricts the representativeness and generalizability of the results. 


\section{Conclusion}

Monitoring local coverage of preventive health services for children is a critical component for achieving the Sustainable Development Goals and improving health outcomes and survival among children in Kenya and similar settings in sub-Saharan Africa. We found a significant gender disparity in vaccine coverage, as females in our study had lower odds of being fully immunized compared to males. Further, females were also found to have lower coverage of vitamin A supplementation and growth monitoring. The gender gap found in this study needs further investigation to elucidate what factors are associated with females having significantly lower vaccination coverage than males. This cross-sectional study was small in nature and consequently, limited in its generalizability. However, it is a critical step in understanding how well national and regional data reflect clinic-level data on health service coverage and the factors that impact coverage. This will ultimately get us closer to realizing the Sustainable Development Goals and improving the health of young Kenyan children.

\section{Abbreviations}

AMPATH - Academic Model Providing Access to Healthcare

BCG - Bacillus Calmette-Guerin

Hib - Haemophilus influenza type b

KDHS - Kenya Demographic Health Survey

$\mathrm{MCH}$ - maternal and child health

OPV - oral polio vaccine

PCV - pneumococcal conjugate vaccine

SSA - sub-Saharan Africa

VAS - vitamin A supplementation

\section{Declarations}

\section{Ethics Approval and consent to participate}

This study was approved by the ethical committees of both Indiana University and Moi University. Moi University's Institutional Research and Ethics Committee is registered with the U.S. Office of Human Research Protections with its own Federalwide Assurances.

Consent for Publication 
Not applicable

\section{Availability of data and materials}

The datasets used and/or analysed during the current study are available from the corresponding author on reasonable request.

\section{Competing interests}

The authors declare that they have no competing interests

\section{Funding}

Dr. McHenry's time was supported in part by a training grant entitled "Training in STIs and Other Infections of Global Health Significance" (T32AI007637, PI: Dr. Wools Kaloustian) from the National Institute of Allergy and Infectious Diseases, Bethesda, MD, USA. The Morris Green Physician Scientist Development Program at Indiana University also supported Dr. McHenry. The role of the funders was to support the time Dr. McHenry spent working on the project.

\section{Authors contributions}

$A D$ made substantial contributions to the conception of the study, wrote the first draft of the manuscript, and analysed and interpreted the data. EO, SA, AO, CM, and RV critically reviewed and substantially revised the manuscript. $\mathrm{MM}$ made substantial contributions to the conception and design, interpretation of data, and substantially revised the manuscript. All authors read and approved the final manuscript.

\section{Acknowledgements}

The authors would like to thank the study participants for their time and invaluable insights. The authors also thank John Paul Spence, PhD, for his contribution in editing the manuscript.

\section{References}

1. UNICEF, WHO, World Bank UN. Levels and Trend in Child Mortality Report 2017. 2017.

2. Boerma T, Requejo J, Victora CG, Amouzou A, George A, Agyepong I, et al. Countdown to 2030: tracking progress towards universal coverage for reproductive, maternal, newborn, and child health. The Lancet. 2018;391(10129):1538-48.

3. Brault MA, Ngure K, Haley CA, Kabaka S, Sergon K, Desta T, et al. The introduction of new policies and strategies to reduce inequities and improve child health in Kenya: A country case study on progress in child survival, 2000-2013. PLoS ONE. 2017;12(8):e0181777.

4. Bryce J, Arnold F, Blanc A, Hancioglu A, Newby H, Requejo J, et al. Measuring Coverage in $\mathrm{MNCH}$ : New Findings, New Strategies, and Recommendations for Action. PLoS Medicine. 2013;10(5):e1001423. 
5. Kenya National Bureau of Statistics, Ministry of Health/Kenya, National AIDS Control Council/Kenya, Kenya Medical Research Institute, Population NCf, Development/Kenya. Kenya Demographic and Health Survey 2014. Rockville, MD, USA; 2015.

6. Mudany MA, Sirengo M, Rutherford GW, Mwangi M, Nganga LW, Gichangi A. Enhancing Maternal and Child Health using a Combined Mother \& Child Health Booklet in Kenya. Journal of tropical pediatrics. 2015;61(6):442-7.

7. Einterz RM, Kimaiyo S, Mengech HN, Khwa-Otsyula BO, Esamai F, Quigley F, et al. Responding to the HIV pandemic: the power of an academic medical partnership. Academic medicine : journal of the Association of American Medical Colleges. 2007;82(8):812-8.

8. Taylor-Robinson DC, Maayan N, Soares-Weiser K, Donegan S, Garner P. Deworming drugs for soiltransmitted intestinal worms in children: effects on nutritional indicators, haemoglobin, and school performance. The Cochrane Database of Systematic Reviews. 2015(7):1-157.

9. Pabalan N, Singian E, Tabangay L, Jarjanazi H, Boivin MJ, Ezeamama AE. Soil-transmitted helminth infection, loss of education and cognitive impairment in school-aged children: A systematic review and meta-analysis. PLoS Neglected Tropical Diseases. 2018;12(1):e0005523.

10. Imdad A, Mayo-Wilson E, Herzer K, Bhutta ZA. Vitamin A supplementation for preventing morbidity and mortality in children from six months to five years of age. Cochrane Database Syst Rev. 2017;3:Cd008524.

11. Baguune B, Ndago JA, Adokiya MN. Immunization dropout rate and data quality among children 1223 months of age in Ghana. Archives of public health = Archives belges de sante publique. 2017;75:18-.

12. IBM. SPSS statistics for Windows 24.0 ed. Armonk, NY: IBM 2016.

13. Berger A. How does herd immunity work? BMJ (Clinical research ed). 1999;319(7223):1466-7.

14. Maina LC, Karanja S, Kombich J. Immunization coverage and its determinants among children aged 12 - 23 months in a peri-urban area of Kenya. The Pan African Medical Journal. 2013;14:3.

15. Kawakatsu Y, Tanaka J, Ogawa K, Ogendo K, Honda S. Effects of three interventions and determinants of full vaccination among children aged 12-59 months in Nyanza province, Kenya. Public health. 2015;129(11):1530-8.

16. Kawakatsu Y, Honda S. Individual-, family- and community-level determinants of full vaccination coverage among children aged 12-23 months in western Kenya. Vaccine. 2012;30(52):7588-93.

17. de Figueiredo A, Johnston IG, Smith DMD, Agarwal S, Larson HJ, Jones NS. Forecasted trends in vaccination coverage and correlations with socioeconomic factors: a global time-series analysis over 30 years. The Lancet Global Health. 2016;4(10):e726-e35.

18. Calhoun LM, van Eijk AM, Lindblade KA, Odhiambo FO, Wilson ML, Winterbauer E, et al. Determinants and Coverage of Vaccination in Children in Western Kenya from a 2003 Cross-Sectional Survey. The American Journal of Tropical Medicine and Hygiene. 2014;90(2):234-41.

19. Ushie BA, Fayehun OA, Ugal DB. Trends and patterns of under-5 vaccination in Nigeria, 1990-2008: what manner of progress? Child: care, health and development. 2014;40(2):267-74. 
20. Mutua MK, Kimani-Murage E, Ngomi N, Ravn H, Mwaniki P, Echoka E. Fully immunized child: coverage, timing and sequencing of routine immunization in an urban poor settlement in Nairobi, Kenya. Tropical Medicine and Health. 2016;44:13.

21. Egondi T, Oyolola M, Mutua MK, Elung'ata P. Determinants of immunization inequality among urban poor children: evidence from Nairobi's informal settlements. International Journal for Equity in Health. 2015;14:24.

\section{Figures}

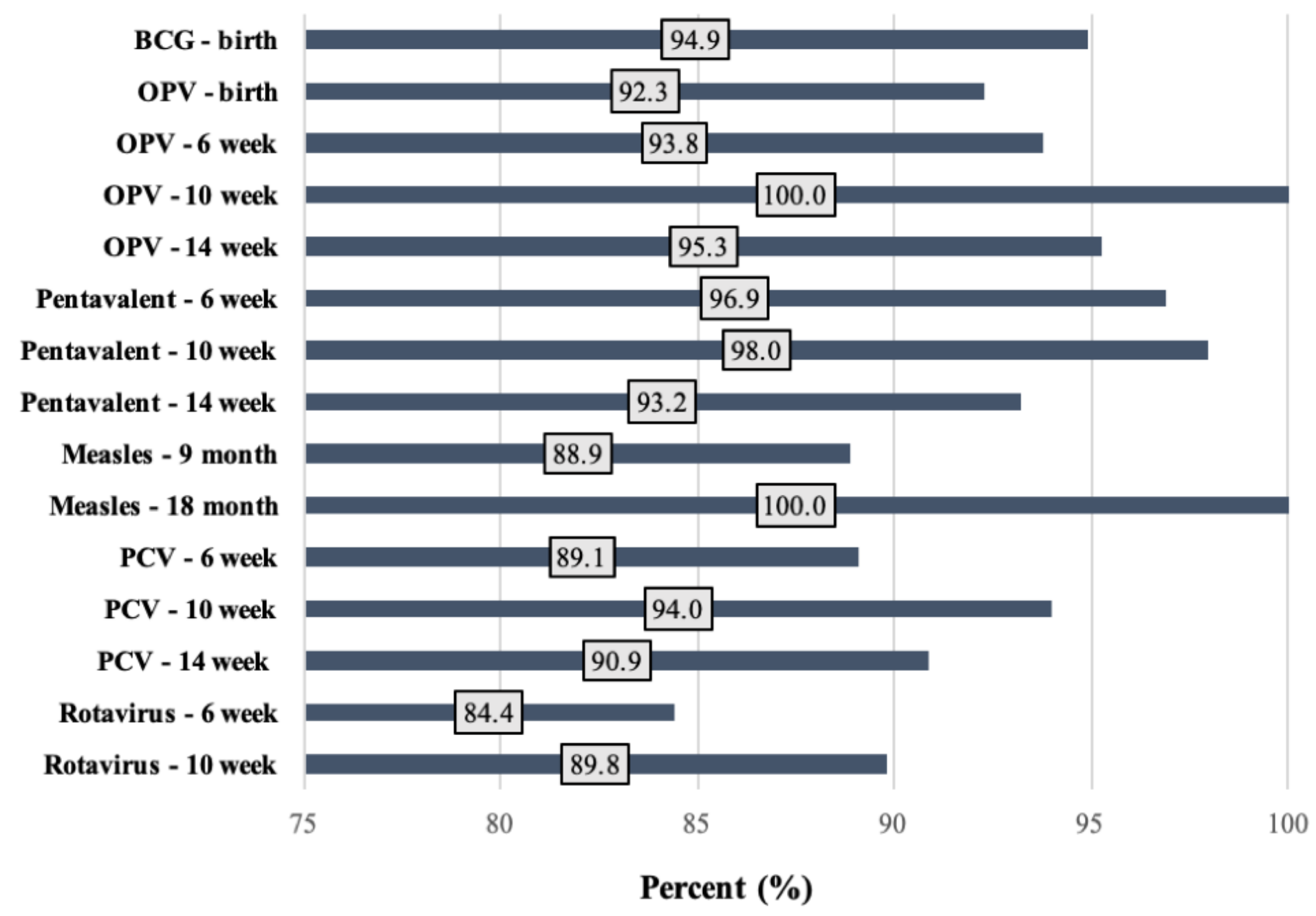

Figure 1

Individual Dose Coverage for Each Vaccine Series 